\title{
O BRINCAR DE CRIANÇAS E SUAS FAMÍLIAS COMO ALTERNATIVA DE CUIDADO À SAÚDE MENTAL INFANTIL
}

CHILDREN AND FAMILIES PLAYING TOGETHER, AS ALTERNATIVE CARE FOR CHILD MENTAL HEALTH

\author{
EL JUEGO DE NIÑOS Y SUS FAMILIAS COMO ALTERNATIVA DE CUIDADO A LA SALUD \\ MENTAL INFANTIL
}

\author{
Vania Bustamante \\ Rosângela Santos Oliveira*
}

\begin{abstract}
RESUMO
Trata-se de um relato de experiência sobre o "Brincando em Família”, projeto de extensão da Universidade Federal da Bahia, que oferece atendimento psicológico em grupo e pode ser livremente frequentado por crianças e suas famílias. $\mathrm{O}$ projeto se sustenta na discussão sobre políticas e práticas de saúde mental infantil e na teoria psicanalítica, particularmente nas contribuições de Winnicott e na perspectiva de Holmes sobre a acolhida. Com base no relato do cuidado oferecido a alguns frequentadores, mostra-se que a acolhida a crianças e suas famílias (envolvendo a oferta de um espaço para brincar e a presença atenta da equipe) propicia avanços terapêuticos e, ao mesmo tempo, fortalece a autonomia dos sujeitos. Destaca-se o potencial do projeto na promoção da saúde e desenvolvimento infantil, detecção precoce e tratamento, recebendo encaminhamentos de diversos setores (educação, assistência social, atenção básica), tornando-se, assim, um serviço importante em uma rede de atenção psicossocial.
\end{abstract}

Palavras-chave: Infância. Saúde mental. Psicanálise. Família.

\begin{abstract}
This paper presents a report about "Family playing" project, which is an extension project from the Federal University of Bahia. This project offers group psychological counseling, which children and their families can join freely. The project is based on the discussion of policies and child mental health practices, and psychoanalytic theory, particularly Winnicott's contributions and Holmes perspective on the reception. Based on the reports about the care provided to some regular attendees, it is shown that the reception of children and their families (which involves offering a space to
\end{abstract}

\footnotetext{
Texto recebido em 19 de junho de 2015 e aprovado para publicação em 20 de outubro de 2016.

"Doutora em Saúde Coletiva, professora no Instituto de Psicologia da Universidade Federal da Bahia (UFBA), psicóloga. E-mail: vaniabus@yahoo.com.

"Especialista em Saúde Mental pela Unicamp), psicóloga pela UFBA. E-mail: r.oliveira@gmail.com.
} 
play and the attentive presence of staff) provides therapeutic advances while at the same time it strengthens the individuals' autonomy. Noteworthy is the potential of the project to promote health and child development, early detection and treatment of problems. The center receives referrals from various sectors (education, social welfare, primary health care), thus making it an important service in a network of psychosocial care.

Keywords: Childhood. Mental health. Psychoanalysis. Family.

\section{RESUMEN}

Se presenta un relato de experiencia sobre "Jugando en Familia", un proyecto de extensión de la Universidad Federal de Bahía, que ofrece atención psicológica en grupo y que puede ser libremente frecuentado por niños y sus familias. El Proyecto se sustenta en la discusión sobre políticas y prácticas de salud mental infantil y en la teoría psicoanalítica, especialmente la contribución de Winniccot y la perspectiva de Holmes sobre la acogida. Con base en el relato del cuidado ofrecido a algunos usuarios, se muestra que la acogida - incluyendo la oferta de un lugar para jugar y la presencia atenta del equipo - estimula avances terapéuticos y al mismo tiempo fortalece la autonomía de niños y sus familias. Se destaca el potencial del Proyecto para promover salud y desarrollo infantil, realizar detección precoz y tratamiento, recibiendo derivaciones de diversos sectores asistenciales, convirtiéndose así en un servicio importante en una red de atención psicosocial.

Palabras clave: Infancia. Salud mental. Psicoanálisis. Familia.

\section{INTRODUÇÃO}

$\mathrm{N}$ este relato de experiência, apresenta-se o trabalho desenvolvido no Projeto "Brincando em Família", um espaço que oferece atendimento em grupo a crianças acompanhadas de seus familiares. O projeto visa ao cuidado da saúde mental e do desenvolvimento infantil, tendo a psicanálise como suporte teórico e técnico e em interlocução com as políticas e práticas de saúde mental.

No Brasil, é cada vez mais expressiva a demanda por cuidados em saúde mental infantojuvenil, apesar de ser um campo ainda dotado de pouca visibilidade. Dados nacionais de 2005 apontam que de 10 a 20\% das crianças e adolescentes sofrem de transtornos mentais (Cunha \& Boarine, 2011).

A recente e tardia inclusão da assistência à saúde mental infantil é uma realidade presente no Brasil e em outros países, a qual está relacionada com a incipiência dos conhecimentos sobre diagnósticos e intervençôes terapêuticas na infância. Ressalta-se que, no campo da psiquiatria, somente a partir da 
década de 1930, a clínica da infância começou a estruturar-se com uma marcada distinção da clínica direcionada aos adultos, além de haver sido constituída uma psicopatologia propriamente infantil. Para isso foi fundamental a contribuição da psicanálise e dos estudos sobre o desenvolvimento infantil (Vicentin, 2006).

No contexto brasileiro, como parte da construção do Sistema Único de Saúde (SUS) e dos avanços da reforma psiquiátrica, a Política de Saúde Mental Infantojuvenil, formulada em 2002, é um esforço para vencer a lacuna assistencial histórica nesse campo, quando o cuidado de crianças com deficiência era delegado a instituições filantrópicas ou associações de pais e familiares. Além desse aspecto, a Política também busca superar a prática institucionalizante da lógica higienista (Amstaldenn, Hoffmann \& Monteiro, 2010).

A referida Política está pautada em uma ética e em uma lógica do cuidado, que envolvem os seguintes princípios:

a) cada criança e adolescente a ser cuidado é um sujeito de direitos responsável por sua demanda;

b) o acolhimento é universal para quem chega ao serviço de saúde;

c) as ações devem ir além do espaço físico do serviço;

d) a intersetorialidade orienta o trabalho; e

e) o território é considerado como o lugar psicossocial do sujeito.

Nesse contexto, está prevista a priorização de duas estratégias: de um lado, a implantação de serviços especializados, os Centros de Atenção Psicossocial; do outro, a articulação de uma rede intersetorial, que visa a promover um cuidado integral para um público que geralmente está inserido em contextos de vulnerabilidade social (Couto, Duarte \& Delgado, 2008).

O Centro de Atenção Psicossocial da Infância e Adolescência (Capsia) é o primeiro dispositivo com base territorial, criado especificamente para organizar a atenção a crianças e adolescentes. É ordenador da rede e porta de entrada do sistema, que também deve contar com leitos em hospitais gerais pediátricos e serviços de urgência e emergência (Brasil, 2005). A rede intersetorial potencial tem como setores de destaque a saúde, a assistência social e a educação (Couto, Duarte \& Delgado, 2008). Entretanto, idealmente, todos os serviços de saúde do território devem compor a rede.

A articulação entre saúde mental e atenção básica é, pois, primordial e tem como diretrizes: apoio matricial da saúde mental às equipes do Programa de 
Saúde da Família (PSF); priorização da saúde mental na formação das equipes da atenção básica; e ações de acompanhamento e avaliação das ações de saúde mental na atenção básica (Lauridsen-Ribeiro \& Tanaka, 2010). Entretanto, na prática, aponta-se a lógica do encaminhamento e da desresponsabilização, a hegemonia do modelo biomédico e a consequente fragmentação dos cuidados (que deveriam ser integrais), como obstáculos para a adequada articulação entre os serviços (Onocko-Campos et al., 2012).

A literatura sobre assistência à saúde mental na infância, em serviços públicos, apresenta estudos com diversas ênfases. Existem trabalhos que caracterizam a demanda de crianças e adolescentes em serviços de saúde mental (Rangel, Bustamante \& Belo, 2015). No entanto alguns autores apresentam experiências bem-sucedidas em Capsia, ambulatórios e clínicas-escola (Carvalho, Medina, Bosseto \& Cruz, 2010; Rañna, 2010). Trabalhos mais recentes apontam avanços e permanências na assistência oferecida na atenção básica: Tszesnioski, Nóbrega, Lima, e Facundes (2015) desenvolvem pesquisa-ação no âmbito de um Núcleo de Apoio à Saúde da Família (NASF), em Recife, Pernambuco, que envolveu intervençõos no território visando à construção de redes de cuidado em saúde mental infantojuvenil. Em contrapartida, Sanches e Amarante (2014) apontam a persistência do processo de medicalização de crianças no campo da saúde mental, com base em um estudo de prontuários de crianças atendidas em um centro de saúde escola no Rio de Janeiro.

Aqui não será possível desenvolver uma revisão sistemática dos estudos que vêm sendo publicados. Será feito um recorte no que diz respeito ao lugar ocupado pelas famílias, já que essa é a dimensão central na proposta do Projeto e objeto deste relato de experiência.

Mascarenhas (2010) enuncia que a relação com o Outro é condição necessária para a estruturação do sujeito, sendo a família o espaço onde esse processo se realiza. Romagnoli (2004) acrescenta que uma estrutura familiar desejante dá suporte à linguagem e é fundamental para a humanização do ser. Assim, afirmase que é no mundo fantasmático da família que o sujeito é introduzido à cultura e acessa o simbólico. Com base nessa convivência, são construídas realidades, diferentes maneiras de enxergar e se colocar no mundo, o que propicia a emersão de crenças e sintomas.

Dessa forma, é preciso considerar que a criança necessita de apoio emocional, social e psicológico, sendo a família responsável diretamente por esse suporte (Monteiroet al., 2012). Ao mesmo tempo, faz-se necessária a oferta de estratégias de cuidado para os familiares (Favero-Nunes \& Santos, 2010), pois, como afirma Cavalcante (2001), não se deve subestimar a complexidade da perturbação 
que afeta as famílias, a potência e amplitude da dor. As angústias podem ser avassaladoras e catastróficas, devendo, por isso, ser seriamente consideradas e cuidadas.

Alguns estudos sobre o lugar das famílias na assistência à saúde mental infantil mostram importantes dificuldades no acesso aos serviços e na assistência recebida. Um estudo realizado por Favero-Nunes e Santos (2010), com mães de crianças com transtornos autísticos, mostrou o percurso traçado por essas mães na busca do diagnóstico e tratamento. Os autores apontam falta de apoio social e dificuldades de acesso a recursos especializados, assim como despreparo dos profissionais em fazer diagnósticos, principalmente em crianças muito novas.

Monteiro et al. (2012) realizaram um estudo com famílias atendidas em um Capsia de Fortaleza. O estudo apontou que os familiares, na maioria das vezes, percebem que o comportamento da criança ou adolescente mudou, sendo considerado anormal e, a partir desse estranhamento, é que se inicia a busca por tratamento. Entretanto a acessibilidade ao serviço especializado ainda é muito difícil devido a fatores como sobrecarga, dificuldade de acesso direto e obstáculos criados pelos serviços de atenção básica que, por muitas vezes, não estão preparados para diagnosticar e encaminhar esses pacientes ao serviço de saúde mental.

Os estudos citados trazem como consenso que as famílias se encontram em condições de elevada vulnerabilidade, devido ao desgaste emocional resultante dos cuidados diários com o portador de sofrimento psíquico. Por isso se deve também ter atenção com a saúde mental da família envolvida no processo, pois ela é a entidade-chave no atual tipo de terapêutica, sendo responsável por promover o contato entre o portador de sofrimento psíquico e os serviços de saúde existentes.

Onocko-Campos (2012) aponta a existência de importantes falhas na atual política pública de saúde mental para crianças, pois as intervenções não observam o contexto, a cultura e as redes do sujeito, ocasionando, muitas vezes, a fragilização dos sujeitos e da família. Ao refletir sobre as funções das políticas públicas em saúde mental para crianças e adolescentes, a autora lembra que uma das maiores provocaçõos de Winnicott teria sido afirmar que "não existe essa coisa chamada bebê" e, com isso, chama a atenção para a relevância da dupla mãebebê. Assim, Onocko-Campos (2012) argumenta que "não há como atendermos crianças gravemente perturbadas, ou em risco sério de sê-lo, sem acolhermos e trabalharmos, também, clinicamente com as suas mães e seu ambiente" (p. 143). Portanto é preciso que serviços de saúde mental, tais como o Capsia, percebam que "o trabalho com a dupla mãe-filho faz parte das suas tarefas primárias e não 
é um acréscimo inesperado!" (p. 143). A autora aponta para a necessidade de que a equipe de profissionais tenha disponibilidade para oferecer um ambiente seguro e acompanhar as reflexões da mãe, comportando-se de forma semelhante ao que Winnicott denomina função paterna. O "Brincando em Família", então, busca dar resposta à lacuna apontada pelos autores mencionados, promovendo o cuidado simultâneo da criança e da sua família.

A seguir, são apresentados alguns conceitos psicanalíticos que sustentam as intervençôes. Aqui a psicanálise é considerada como um saber que contribui para um campo heterogêneo (Amarante, 2007 citado por Brandão Júnior \& Besset, 2012) e que tem como característica central construir uma clínica de cada sujeito em sua singularidade (Rinaldi, 2015).

\section{FUNDAMENTOS TEÓRICOS E TÉCNICOS DO PROJETO BRINCANDO EM FAMÍLIA}

O trabalho com crianças desde o início teve um lugar polêmico na psicanálise. Melanie Klein foi a primeira a mostrar que as crianças podiam ser analisadas de forma semelhante aos adultos, porém utilizando como recurso o brincar. Isso fez parte de uma disputa com Anna Freud (na Sociedade Britânica de Psicanálise, na década de 1930), que considerava que as crianças não poderiam ser analisadas, pois estas não faziam transferência e, sendo assim, só era possível realizar intervenções de cunho pedagógico, pelo contato com os pais (Segal, 1975). Desde então, muitos autores têm se debruçado sobre esse campo. Destaca-se o trabalho de Françoise Dolto, na França, que divulgou a psicanálise para o grande público e chamava a atenção sobre a necessidade de tratar as crianças como sujeitos (Dolto, 2004). Dolto criou a "Casa Verde", um espaço que acolhia crianças pequenas e suas famílias, primeira iniciativa a inspirar o Projeto Brincando em Família.

Em Winnicott (pediatra e psicanalista inglês, contemporâneo de Klein), há um aprofundamento no que tange à Psicanálise infantil, uma vez que seu trabalho tem como tema central a criança e sua relação com o ambiente. $\mathrm{O}$ cerne da teoria de Winnicott está na díade mãe-bebê. Não é possível haver um bebê sem que haja os cuidados maternos, em razão da "dependência absoluta", marca dos primeiros meses de vida do bebê para com a mãe.

Winnicott aponta que o ser humano tem uma tendência inata ao desenvolvimento, no entanto depende de um ambiente favorável. Assim, a condição de bem-estar proporcionada à criança é atributo de uma mãe (ou quem faça a maternagem) "suficientemente boa", que é sensível às necessidades do bebê. 
Só na presença dessa mãe suficientemente boa pode a criança iniciar um processo de desenvolvimento pessoal e real. Se a maternagem não for boa o suficiente, a criança torna-se um acumulado de reações à violação; o self verdadeiro da criança não consegue formar-se, ou permanece oculto por trás de um falso self que a um só tempo quer evitar e compactuar com as bofetadas do mundo (Winnicott, 2005, p. 24).

Winnicott (2000) trata da "preocupação materna primária", um estado psicológico em que a mãe se adapta de forma sensível e delicada ao bebê, de modo a (co)responder às suas necessidades que, inicialmente, são corporais. A mãe se identifica com o bebê, colocando-se no lugar dele, suscitando a ilusão no recém-nascido de que é ele quem cria os objetos, mantendo-o, assim, dependente dela. A essa fase Winnicott denominou de "dependência absoluta", e as falhas ocorridas aqui são sentidas pelo bebê como aniquilações do ser. Conforme o recém-nascido sinaliza seu amadurecimento e suas necessidades passam também a ser necessidades de ego, isso o torna apto a suportar as falhas maternas e, aos poucos, pode encaminhar-se para a fase de "dependência relativa", quando as falhas já são compreendidas como frustrações e o capacitam a começar a existir.

Como se evidencia a seguir, o brincar é central na teoria winnicottiana. Winnicott compreende o brincar como expressão da "área intermediária" de experimentação, caracterizada por sua neutralidade, visto que não pode ser contestada e que, apesar de contemplar a realidade interna e externa do sujeito, as mantém separadas. Os fenômenos transicionais (como balbucios) e os objetos transicionais (ponta do cobertor) iniciam o ser humano nessa importante área: "A criança traz para dentro dessa área da brincadeira objetos ou fenômenos oriundos da realidade externa, usando-os a serviço de alguma amostra derivada da realidade interna ou pessoal" (Winnicott, 1975, p. 76). Tal espaço é necessário para que a criança possa sair da fase de "dependência absoluta" na relação com a mãe para a fase de "dependência relativa" (no início de um relacionamento entre a criança e o mundo), pois, pelos fenômenos e objetos transicionais, exerce função de amparo no processo de desilusão.

Em sua prática pediátrica, Winnicott (1982) manteve-se atento ao brincar das crianças pequenas, a exemplo do que chamou de jogo das espátulas, quando se observava qual seria a reação das crianças em contato com espátulas deixadas à sua disposição. Winnicott (1975) defende que o brincar por si mesmo é terapêutico, pois fazer com que as crianças brinquem possibilita a construção de um espaço criativo e é "somente sendo criativo que o indivíduo descobre o eu (self)" (pp. 79-80). O psicoterapeuta, então, trabalha com o material, o conteúdo do brincar que, segundo Winnicott, refere-se à fantasia inconsciente. O brincar é compreendido, também, como primário e promotor de saúde. Nas suas palavras: 
O brincar facilita o crescimento e, portanto, a saúde; o brincar conduz aos relacionamentos grupais; o brincar pode ser uma forma de comunicação na psicoterapia; finalmente, a psicanálise foi desenvolvida como forma altamente especializada do brincar, a serviço da comunicação consigo mesmo e com os outros (Winnicott, 1975, p. 63).

Com base nas contribuições de Winnicott, o Brincando em Família é proposto como um espaço suficientemente bom, favorecedor da tendência humana ao desenvolvimento. É um lugar que acolhe os gestos espontâneos e amplia os fenômenos transicionais, enriquecendo, assim, a capacidade humana de brincar e de sentir que a vida vale a pena ser vivida, o que, para Winnicott, pode ser a principal conquista de um processo analítico (Fulgencio, 2011).

O Projeto foi criado em 2010, e é uma atividade permanente de extensão da Universidade Federal da Bahia (UFBA). Suas atividades são realizadas dois dias por semana, em turnos diferentes, dentro de uma biblioteca pública da cidade de Salvador. Existe uma equipe diferente de acolhedores em cada turno, composta por uma psicóloga e três ou quatro estudantes de Psicologia.

A proposta é que o atendimento às crianças ocorra coletivamente, envolvendo os acolhedores e também as famílias dos pacientes, de modo que crianças e adultos possam interagir e se comunicar de forma livre. As sessões são realizadas em uma sala ampla, onde brinquedos, jogos e materiais gráficos estão à disposição, e os participantes podem escolher o modo de estar no espaço.

Inserido na rede de serviços de atenção psicossocial de Salvador, o Projeto é um dispositivo de saúde que oferece atendimento psicológico para a promoção do desenvolvimento e da saúde mental, com atenção às queixas, com base no brincar. É um espaço que está disponível tanto para famílias que chegam com alguma demanda específica quanto para quem busca apenas um lugar lúdico e de socialização.

No primeiro contato, um acolhedor se coloca disponível para que a família exponha as questões que a trazem. Percebe-se que, neste momento inicial, os cuidadores falam de suas inquietaçóes e da dinâmica familiar, inclusive nos casos em que necessariamente não se expõem queixas.

A principal regra do Projeto é que as crianças devam estar acompanhadas por um cuidador adulto. O funcionamento é explicado para os participantes, e a equipe solicita ao acompanhante alguns dados das crianças, como o nome dela e do cuidador, grau de parentesco, data de nascimento, entre outros. Como também é um espaço de pesquisa, os participantes são convidados a assinar o Termo de Consentimento Livre e Esclarecido (TCLE) para que os seus dados possam ser utilizados em trabalhos acadêmicos. 
O Brincando em Família também oferece "devolutiva" às famílias que trazem demandas ou queixas. $\mathrm{O}$ acolhedor comunica à família que, a partir do quinto encontro, a equipe poderá dialogar sobre o que foi percebido da criança e suas relações, elaborando um psicodiagnóstico processual. Tal diagnóstico não implica uma categoria nosológica, mas a compreensão dos principais processos individuais e familiares que marcam a vida da criança. $\mathrm{O}$ objetivo da devolutiva é, acima de tudo, fazer com que a criança continue frequentando o espaço, construindo, junto com a família, os objetivos que se pretendem alcançar.

O trabalho é pensado na perspectiva da acolhida, que, segundo Rouvray (2009, p. 42), "Não se trata de curar nem de educar". Buscam-se intervenções centradas no apoio aos pais, tornando-os mais seguros e capazes de refletir sobre a relação que existe entre as dificuldades de seus filhos e sua própria história de vida. $\mathrm{O}$ acolhedor trabalha com a escuta analítica, mas as intervençôes são adaptadas ao diferente enquadre que é estabelecido, pois a presença conjunta de crianças e pais exige que haja sutileza e manejo, possibilitando o apoio a ambas as partes.

A transferência é "a mola mestra do trabalho conjunto de análise" (Freud, 1925/2006, p. 47) ${ }^{1}$, condição de sucesso de um tratamento e também um ponto que precisa ser bem trabalhado para que não insurja como resistência. Para o trabalho da acolhida, o manejo da transferência é tido como imprescindível, uma vez que o vínculo transferencial está deslocado visto que todas as pessoas (acolhedores e usuários) interagem e intervém no processo um do outro.

O estudo desenvolvido por Holmes (2012) é uma referência importante para Brincando em Família. O autor descreve o método da acolhida que orienta o trabalho na "Casa de la Familia", projeto que funciona em Lima, no Peru, e que também inspirou o Brincando em Família. Segundo Holmes (2012), a acolhida é o eixo central do atendimento em grupo com crianças e seus familiares, desdobrando-se em quatro elementos: aceitação, conexão, brincadeira e empoderamento.

A "aceitação" é necessária para que o sujeito seja pensado em sua singularidade, sendo cada membro da família considerado um indivíduo. Os comportamentos dos cuidadores e da criança são (quase) sempre aceitos, e apenas os pontos positivos desses comportamentos são comentados, não importando quão negativos eles possam parecer, já que o julgamento tem efeito devastador para a criança e para a família.

Fala-se em um encontro caloroso, com entusiasmo, como estratégia de efeito terapêutico. As intervenções são realizadas sempre no sentido de encorajar

1 A primeira data indica o ano de publicação original da obra, e a segunda, a edição consultada pelo autor e só será pontuada na primeira citação da obra no texto. Nas seguintes, será registrada apenas a data de publicação original. 
a reflexão do cuidador, "conectar" os sentimentos que envolvam a família, colocando a criança no centro do diálogo e deixando-a a par do que se trata. $\mathrm{O}$ "brincar" é visto da mesma forma que na terapia psicodinâmica do consultório, ou seja, é não estruturado, centrado na criança, não intrusivo, e os acolhedores podem se envolver na brincadeira. $\mathrm{O}$ "empoderamento" é considerado como mecanismo terapêutico, visto que promove a independência das famílias sem responder, sugerindo soluções, fazendo com que as pessoas reflitam sobre si mesmas. As famílias, não raro, chegam com diagnósticos e com rotulações sobre as crianças e, nesse contexto, as intervenções no sentido de empoderá-las, questionando e validando o que elas acham.

Holmes (2012) destaca que as famílias vêm ao espaço à procura de ajuda, por isso os acolhedores devem aceitá-las, sendo calorosos e empáticos. Aponta, ainda, que esse tipo de adaptação favorece àquelas pessoas que não poderiam, por diversos motivos, ter análise em um consultório. É como se o espaço se configurasse como um terceiro na relação com as famílias, servindo de suporte para elas.

A segui, serão descritos alguns aspectos do trabalho desenvolvido no Brincando em Família e apresentados três casos considerados típicos do público que frequenta o espaço.

\section{CUIDADO ÀS CRIANÇAS E SUAS FAMÍLIAS}

Existe uma diversidade no que diz respeito à composição dos arranjos das famílias que frequentam o projeto. Algumas estão estruturadas de maneira convencional: mãe, pai e filho(s). Há outras, no entanto, em que a figura de referência de cuidado é a avó ou tia, e é esta que participa do Projeto. Existem também famílias em que os pais estão em processo de separação ou, ainda, o papel paterno não é exercido pelo pai, havendo ou não a sua existência. Registrase, ainda, a existência de famílias em que a mãe é a única figura de referência ou que o cuidado da criança é retirado dos pais e entregue aos avós. Com menos frequência, encontram-se famílias homoparentais.

Existe variabilidade nas realidades socioeconômicas e níveis de escolaridade. Tal fato pode ser atribuído ao caráter gratuito do projeto e à sua localização em um bairro do Centro de Salvador, por onde circulam pessoas de diferentes níveis de renda.

Os motivos verbalizados para frequentar o espaço são variados. Entre maio e outubro de 2012, aproximadamente 53 famílias participaram do projeto, levando uma ou mais crianças, destas 26 não apresentaram uma queixa específica. As outras 27 levaram demandas várias, como se observa na tabela 1 . 
Tabela 1. Principais queixas entre os frequentadores do Projeto Brincando em Família

\begin{tabular}{ll}
\hline \multicolumn{1}{c}{ Queixa predominante } & N. \\
\hline $\begin{array}{l}\text { Problemas de comportamento: agressividade, } \\
\text { “hiperatividade”, agitação na escola e em casa. }\end{array}$ & 7 \\
$\begin{array}{l}\text { Dificuldades de aprendizagem e desinteresse pela } \\
\text { escola. }\end{array}$ & 7 \\
$\begin{array}{l}\text { Preocupações em torno do desenvolvimento. } \\
\text { Dificuldades de interação: timidez excessiva, “questões } \\
\text { depressivas". }\end{array}$ & 3 \\
Necessidade de interação dos pais com os filhos. & 7 \\
\hline Total de crianças que apresentaram queixas: & 3 \\
\hline
\end{tabular}

Fonte: elaborado pelas autoras.

Considera-se que a família não apresenta uma queixa específica quando procura um espaço de socialização e brincadeira ou chega casualmente. Porém, com o desenvolver do processo, podem surgir demandas. Outras vezes, trata-se de crianças que chegam ao Projeto por indicação de famílias que já o frequentavam ou vêm acompanhando uma criança que apresenta alguma queixa e, dessa forma, beneficia-se de um ambiente de brincadeiras e socialização.

Por motivos de espaço, não será possível realizar uma reflexão sobre a dificuldade apontada na literatura para caracterizar as queixas que chegam aos serviços de saúde mental (Rangel et al., 2015). A categorização apresentada aqui diz respeito aos motivos verbalizados espontaneamente pela família nos primeiros encontros, o que certamente está longe de caracterizar um diagnóstico.

\section{A EXTENSA FAMÍLIA DE GUILHERME E A PROCURA POR UM LUGAR PARA BRINCAR}

Dessa família, chegaram ao projeto Gabi e os seus três filhos mais novos: Gustavo (15), ${ }^{2}$ Giovana (12) e Guilherme (9 meses). A demanda inicial foi a de estar em um ambiente em que Guilherme pudesse interagir com crianças de sua idade. O primeiro a conhecer o Projeto foi Gustavo, que era frequentador da biblioteca. Em seguida, Gabi passou a frequentar o Projeto, juntamente com Guilherme, alternando a presença dos filhos mais velhos. Após alguns encontros, a equipe percebeu diversos aspectos da dinâmica familiar, sendo realizadas intervenções pontuais para cada vínculo.

Gabi expressou preocupação em relação ao desenvolvimento do filho (“Guilherme está mordendo muito as pessoas, será que isso é normal?”) e pôde

2 Todas as idades referidas neste trabalho se referem ao momento em que cada família começou a frequentar o Projeto. Vale destacar que, para proteger a identidade dos participantes, todos os nomes usados aqui são fictícios. 
falar sobre isso com os acolhedores e com outros frequentadores do espaço. A acolhida foi fundamental para que a genitora refletisse sobre os comportamentos do filho e pudesse compreendê-los como naturais à sua faixa etária. Os acolhedores respondiam aceitando as preocupações de Gabi e, ao mesmo tempo, perguntando o que ela própria pensava sobre o comportamento do filho, propiciando assim movimentos de empoderamento.

Por outro lado, o espaço mostrou-se terapêutico para Gabi, já que essa relatou apresentar episódios de ansiedade durante sua vida, podendo falar sobre as suas angústias e partilhar experiências com outras mães. Também pôde observar seu filho mais novo de outra forma, projetando menos nele suas inseguranças e medos.

Quanto aos filhos mais velhos, a função que ela atribuía a eles foi se modificando. No início do contato, os adolescentes dividiam com a mãe o cuidado de Guilherme. A acolhida oferecida possibilitou, além de (re)significar o olhar da mãe sobre os filhos, desencadear e, ou, facilitar o processo de socialização, desenvolver a capacidade social da criança (o prazer da troca), enfrentar desacordos e conflitos com manejo e sem violência (promover vínculos). "Guilherme deu seu primeiro passo no Brincando em Família." Esse evento é lembrado por Gabi todas as vezes que a família retorna ao espaço, hoje de um modo esporádico.

\section{5 "SÓ VOU EMBORA QUANDO VOCÊS ME TIRAREM DAQUI": A ASSIDUIDADE DE AMANDA E ARTUR}

Amanda (30) e Artur (7) foram encaminhados por um profissional de uma Vara de Família. Frequentaram o Projeto por aproximadamente um ano. No relato do encaminhamento, foi referido que mãe e criança sofreram agressões verbais por parte do pai, estando a criança emocionalmente abalada e retraída. Amanda relatou que se separara do pai de Artur havia poucos meses e fora morar com a irmã mais velha, com quem tinha uma relação de dependência.

Inicialmente, Amanda chegava ao projeto de forma retraída, sem expressar suas vontades. Parecia estar seguindo sempre as orientações da irmã. Após alguns encontros, Amanda começou a apresentar seus desejos e afirmou que frequentar o Projeto era uma necessidade dela. Um dia, ela afirmou: "Só vou embora quando vocês me tirarem daqui". Dessa forma, o espaço passou de um lugar para o cuidado do filho, para um lugar terapêutico também para a mãe. Tornou-se um espaço "suficientemente bom", na perspectiva winnicottiana, onde suas necessidades de vínculo e sustentação puderam ser supridas. Aos poucos, Amanda foi expressando inquietações e se dispondo a novas experiências, tanto no sentido de se envolver com atividades que poderiam conduzi-la a ter independência financeira quanto na dimensão afetiva, ao iniciar um novo relacionamento amoroso. 
Artur demonstrava interesse em brincar de super-herói e sempre repetia a mesma brincadeira durante sua participação no Projeto. O espaço possibilitou a Artur expressar seus ressentimentos e angústias e se sentir acolhido. Ali ele não tinha de cuidar para que a mãe não ficasse "nervosa" e brigasse, ou "ficar quieto" para evitar conflitos. Por isso demonstrava certa tristeza e dificuldade em sair do ambiente, como uma forma de prolongar o prazer em descarregar suas angústias. Artur nos abraçava forte como querendo um pedaço de nós, do momento, para levar consigo.

O Projeto ofereceu ainda a possibilidade de avançar em um processo de aproximação com a figura paterna, que implicava também que a presença do pai na vida da criança fosse reconhecida e que Artur pudesse adotar uma posição ativa diante daquela figura, expressando seus desejos e necessidades.

\section{A AGITAÇÃO DE MARCOS}

A família foi encaminhada por uma psicóloga que trabalhava em uma unidade de saúde de Salvador. Ele frequentou assiduamente o Projeto durante alguns meses. Foi possível ouvir as queixas, fazer uma avaliação psicodiagnóstica e conversar com a família, propondo objetivos para frequentar o espaço.

Marcos era o mais novo dos três filhos de Marta. Seus irmãos, Manoel (8 anos) e Maria (12 anos), eram filhos de outro pai. A família morara durante três anos na casa de uma tia. Recentemente, mudou-se para a casa da avó materna. Marcos nunca tivera contato com o pai. Marta expressou que não queria qualquer contato do filho com o pai, devido ao envolvimento deste com "coisas erradas", como o uso de bebidas e drogas.

Embora a mãe fosse a cuidadora principal, a família materna costumava oferecer suporte financeiro e emocional. Os meninos tinham como figura de referência forte uma prima adolescente, que, inclusive, visitou o Projeto, além de um tio materno que morava com eles. A mãe cursou o ensino médio e não trabalhava havia algum tempo.

Marta expressou que o filho era "muito agitado, agressivo, impaciente e impulsivo", que a escola sugerira que o filho recebesse acompanhamento psicológico e esboçou a possibilidade do diagnóstico de TDAH.

A partir da avaliação dos encontros e das brincadeiras e jogos, percebeuse a falta de limites no comportamento de Marcos, a passividade e ausência de intervenções incisivas por parte da mãe, assim como a aceitação do irmão Manoel, que costumava ceder aos gritos e lágrimas do irmão, após as solicitaçôes feitas pela mãe. 
Nada identificamos como causas cognitivas ou biológicas. Encontramos suporte na perspectiva winnicotiana, que compreende a agressividade em crianças pequenas como resultado de influências ambientais bem como uma possível inibição da agressividade dos pais. O comportamento de Marta corroborava essa compreensão, uma vez que, em seu discurso, ela trazia uma grande sobrecarga emocional, além de muita passividade diante da vida e de suas dificuldades financeiras ou de saúde.

Pensou-se, também, que a agitação de Marcos poderia ser entendida como a expressão de uma falta de lugar na própria família e um movimento de procura por esse lugar. De algum modo, os sintomas de Marcos movimentaram a família para procurar ajuda, propiciando melhoras para o grupo familiar (Mascarenhas, 2010).

Durante os encontros, percebemos em Marcos uma necessidade de se expressar que emergia por meio de gritos e lágrimas. Após as intervenções feitas por acolhedores, ele resistia em escutar inicialmente, mas logo acolhia o que the era dito, mostrando compreensão. No que se referia a Manoel, percebemos que a forma de manifestação de Marcos ocupava muito espaço e atenção, causando uma inibição de seu próprio comportamento.

Marta expressou alívio quando a equipe a convocou a refletir sobre os aspectos subjetivos e relacionais dela com o filho e, em forma conjunta, descartou-se a hipótese diagnóstica de TDAH. Afirmou se sentir apoiada pela equipe para lidar mais firmemente com os filhos. Foi possível perceber um posicionamento mais ativo de Marta diante da agitação e agressividade de Marcos no Projeto. Todos os esforços de Marta eram aceitos pela equipe, que procurava também realizar a conexão entre o comportamento do filho e as respostas da mãe.

Após alguns meses (e coincidindo com um período de recesso), a família parou de frequentar o Projeto. Ao receber uma ligação habitual de acompanhamento, Marta relatou que voltou a trabalhar e expressou o seu desejo de voltar ao Brincando em Família quando tivesse tempo. O retorno ao trabalho foi entendido como uma expressão de empoderamento por parte de Marta.

\section{SOBRE A SINGULARIDADE DO BRINCAR "EM FAMÍLIA": DESAFIOS, POSSIBILIDADES E LIMITES}

Os relatos sobre as famílias atendidas mostram que o Projeto tem possibilidade de acolher diversas queixas (preocupações em torno do desenvolvimento infantil, "agressividade", manifestaçôes depressivas, entre outras) vindas de múltiplos arranjos familiares e também de instituições diversas que fazem os encaminhamentos: educação, sistema de garantia de direitos, saúde, etc. 
Considera-se o Projeto como uma experiência bem-sucedida, no que concerne ao acolhimento de crianças e seus familiares com demandas que não puderam ser atendidas na atenção básica (já que as famílias evidenciaram a necessidade de um lugar que respeitasse o tempo e o modo de cada um estar no espaço). Por outro lado, trata-se de queixas que não demandam serviços de alta complexidade como o Capsia, inclusive porque não se considera que as crianças requeiram tratamentos de longo prazo. As intervenções realizadas contribuem para fortalecer a criança e sua família e, de algum modo, reverter processos de cristalização de queixas, tais como "agressividade" ou "agitação".

É importante destacar que, embora o atendimento aconteça em um espaço coletivo, não se trata de um grupo terapêutico, pois cada indivíduo é ouvido em sua singularidade e cada família é acolhida no seu modo singular de frequentar o espaço. O Projeto acolhe pessoas que precisam falar sobre as suas queixas bem como aquelas que não desejam ou não podem falar.

Também é preciso reconhecer que a proposta tem importantes limitaçôes, pois o processo terapêutico somente acontece conforme a família se dispõe a frequentar o Projeto e, quando esta deixa de frequentá-lo, muitas questóes ficam em aberto. Por outro lado, vale lembrar que a interrupção precoce do tratamento pode acontecer em qualquer modalidade de atendimento. Quando se trata de serviços que funcionam em atendimentos individuais e com hora marcada, habitualmente, os usuários que faltam perdem a vaga. No Brincando em Família, o espaço permanece disponível para quando as famílias desejarem retornar, o que, por si só, pode ser um fator (re)assegurador para os usuários. Outras limitações do serviço estão relacionadas com o seu caráter de projeto de extensão e o fato de não contar com financiamento, o que dificulta, entre outras coisas, investir mais no contato com as instituiçôes que encaminham as crianças e suas famílias.

Novos recortes de pesquisa deverão ser desenvolvidos para continuar refletindo sobre o potencial e os desafios de um trabalho de orientação psicanalítica que cuida, ao mesmo tempo, das crianças e de suas famílias. Acredita-se que este relato de experiência mostrou que se trata de uma aposta em que vale a pena investir. 


\section{REFERÊNCIAS}

Amstalden, A. L. F., Hoffmann, M. C. C. L. \& Monteiro, T. P. M. (2010). A política de saúde mental infanto-juvenil: seus percursos e desafios. In E. Lauridsen-Ribeiro \& O. Y. Tanaka (Orgs.), Atenção em saúde mental para crianças e adolescentes no SUS. (pp. 33-45). São Paulo: Hucitec.

Brandão Júnior., P. M. \& Besset, V. L. (2012). Psicanálise e saúde mental: contextualizando o atendimento às demandas. Psicologia USP, 3(23), 523-538.

Brasil. Ministério da Saúde. (2005). Caminhos para uma política de saúde-mental infanto-juvenil. Brasília: Secretaria de Atenção à saúde.

Carvalho, C. A. C., Medina, R. M., Bosseto, S. \& Cruz, T. A. (2010). Grupo de acolhimento: relato de experiência. In E. Lauridsen-Ribeiro \& O. Y. Tanaka (Orgs.), Atenção em saúde mental para crianças e adolescentes no SUS. (pp. 248260). São Paulo: Hucitec.

Cavalcante, F. (2001). Família, subjetividade e linguagem: gramáticas da criança "anormal". Ciência e saúde coletiva, 6(1), 125-137.

Couto, M. C. V., Duarte, C. S. \& Delgado, P. G. G. (2008). A saúde mental infantil na Saúde Pública brasileira: situação atual e desafios. Revista Brasileira de Psiquiatria, 30(4), 311-322.

Cunha, C. C. \& Boarine, M. L. (2011). O lugar da criança e do adolescente na Reforma Psiquiátrica. Revista Psicologia e Saúde, 3(1), 68-76.

Dolto, F. (2004). La causa de losniños. Buenos Aires: Paidós.

Favero-Nunes, M. A. \& Santos, M. A. (2010). Itinerário terapêutico percorrido por mães de crianças com transtorno autístico. Psicologia, Reflexão e Crítica, 23(2), 208-221.

Freud, S. (1925). Um estudo autobiográfico. In J. Salomão (Trad.), Ediçãao standard das obras psicológicas completas de Sigmund Freud (Vol. 20, pp. 15-78). Rio de Janeiro: Imago, 2006. (Publicado originalmente em 1925).

Fulgencio, L. (2011). A constituição do símbolo e o processo analítico para Winnicott. Paidéia, 21(50), 392-401.

Holmes, J. (2012). A model of intervention at a psychoanalytic parent-child drop-in group in a poor district of Lima-Peru. Jornal of Child Psychoterapy, 38(2), 170-184. 
Lauridsen-Ribeiro, E. \& Tanaka, O. Y (2010). Organização de serviços no SUS para o cuidado de crianças e adolescentes com problemas de saúde mental. In E. Lauridsen-Ribeiro \& O. Y. Tanaka (Orgs.), Atenção em saúde mental para crianças e adolescentes no SUS. (pp. 147-169). São Paulo: Hucitec.

Mascarenhas, C. F. (2010). As famílias e suas crianças. In L. A. B. Trad (Org.), Família contemporânea e Saúde: significados, práticas e políticas públicas. (pp. 227-241). Rio de Janeiro: Fiocruz.

Monteiro, A. R. M., Teixeira, L. A., Silva, R. S. M. da, Rabelo, K. P. S., Tavares, S. de F. do V. \& Távora, R. C. de O. (2012). Sofrimento psíquico em crianças e adolescentes: a busca pelo tratamento. Escola Anna Nery, 16(3), 523-529.

Onocko-Campos, R. T. (2012). Psicanálise e saúde coletiva. São Paulo: Hucitec.

Onocko-Campos, R. T., Campos, G. W. de S., Ferrer, A. L., Corrêa, C. R. S., Madureira, P. R. de, Gama, C. A. P. da, . . Nascimento, R. (2012). Avaliação de estratégias inovadoras na organização da Atenção Primária à Saúde. Revista de Saúde Pública, 46(1), 43-50.

Rangel, L., Bustamante, V. \& Belo, G. (2015). Caracterização de usuários atendidos em um serviço de saúde mental infantil em salvador. Psicologia em Estudo, 20(2), 273-284.

Ranña, W. (2010). A saúde mental da criança na atenção básica: detecção e intervenção a partir do Programa de Saúde da Família e do apoio matricial. In E. Lauridsen-Ribeiro \& O. Y. Tanaka (Orgs.), Atenção em saúde mental para crianças e adolescentes no SUS. (pp. 170-185). São Paulo: Hucitec.

Rinaldi, D. L. (2015). Micropolítica do desejo: a clínica do sujeito na instituição de saúde mental. Ciência e saúde coletiva, 20(2), 315-323.

Romagnoli, R. C. (2004). O sintoma da família: excesso, sofrimento e defesa. Interaçôes, 9(18), 41-60.

Rouvray, C. (2009). La acogida a padres y niños. In B. Maza (Ed.), La casa de la família: una contribuición psicoanalítica a la salud pública en Perú. (pp. 37-63). Lima: Universidad Nacional Mayor de San Marcos.

Sanches, V. N. L. \& Amarante, P. D. de C. (2014). Estudo sobre o processo de medicalização de crianças no campo da saúde mental. Saúde debate, 38(102), 506-514. 
Segal, H. (1975). Introdução à obra de Melanie Klein. Rio de Janeiro: Imago.

Tszesnioski, L. de C., Nóbrega, K. B. G. da, Lima, M. L. L. T. de \& Facundes, V. L. D. (2015). Construindo a rede de cuidados em saúde mental infantojuvenil: intervenções no território. Ciência e Saúde Coletiva, 20(2), 363-370.

Vicentim, M. C. G. (2006). Infância e adolescência: uma clínica necessariamente ampliada. Revista de Terapia Ocupacional, 17(1), 10-17.

Winnicott, D. W. (1975). O brincar e a realidade. Rio de Janeiro: Imago.

Winnicott, D. W. (1982). A observação de bebês em uma situação estabelecida. In D. W. Winnicott, Textos selecionados: da pediatria à psicanálise. (pp. 139163). Rio de Janeiro: Francisco Alves.

Winnicott, D. W. (2000). A preocupação materna primária. In D. W. Winnicott, Da pediatria à psicanálise: obras escolhidas por D. W. Winnicott. (pp. 399-405). Rio de Janeiro: Imago.

Winnicott, D. W. (2005). A família e o desenvolvimento individual. São Paulo: Martins Fontes.

\section{AGRADECIMENTOS}

A Adriana Correia, Ayla Arapiraca Galvão e Hortência Conceição que, como estagiárias do Projeto Brincando em Família, em 2013, participaram da produção dos dados clínicos utilizados neste trabalho. 